\title{
World Federation for Culture Collections
}

\author{
Minutes of the Meeting of the Executive Board, 16 October 1992, Beijing
}

Minute 1. Call to order. A meeting of the newly elected Executive Board (EB) of the World Federation for Culture Collection (WFCC) was called to order at 4:30 p.m. on 16 October 1992 at the end of the Seventh International Congress of Culture Collections (ICCC-VII) (theme, biodiversity and the role of culture collections) at the International Convention Center, Beijing.

Minute 2. Record of attendance. The Board consisted of Dr. L. Sly (Australia), President; Dr. V. Canhos (Brazil), Vice President; Dr. D. Fritze (Germany), Secretary; Dr. D. van der Mei (The Netherlands), Treasurer; Mrs. B. Brandon (U.S.A.); Dr. T. Deak (Hungary); Dr. C. Kurtzman (U.S.A.); Dr. T. Nakase (Japan); Dr. G. Pinaev (Russia); Dr. A. Ventosa (Spain); Mrs. B. Kirsop (United Kingdom), Past President; ex-officio member Dr. H. Sugawara (Japan), Director, World Data Center on Microorganisms (WDC); and invited guest Dr. D. Smith (United Kingdom), Chair, Committee on Postal, Quarantine, and Safety Regulations. The EB member unable to attend the meeting was Dr. D. Hawksworth (United Kingdom).

Minute 3. Minutes of the last meeting and matters arising. Minutes: Agreed; see minutes of the General Assembly. Matters arising: Mrs. B. Kirsop proposed that the four Biotechnology Books (Living Resources for Biotechnology) could be reissued in a combined volume. It was agreed that the discussion should be led by the Education Committee that would report to the EB. It was also agreed that work on the Technical Information Sheets should be continued but that material must be checked for up-to-dateness before distribution; it was proposed that Dr. K. A. Malik should send all material to Dr. C. Kurtzman first for circulation to the EB before new issuance.

The proceedings of the First and Second International Symposia on Endangered Culture Collections, 1987 and 1988, have finally been printed and will be stored with the Secretary. Dr. L. Sly said that letters returning thanks to authors will be sent. Availability of this book (free of charge, but postage covered) should be announced in the next WFCC newsletter.

Minute 4. Executive Board. The Board, except for the 12th member, had been elected through postal ballot. Dr. D. van der Mei agreed to continue as Treasurer, and Dr. D. Fritze was proposed as the Secretary. This was accepted. A proposal was made to include Dr. (Mrs.) Zenglin Yuan, Curator of the Pathogenic Bacteria Collection in Beijing, China, as the 12th member. Dr. K. Paknikar from Pune, India, was proposed as the new Editor for the WFCC newsletter.

Minute 5. Committees. The old committees were dissolved. The new committees are as follows.

(i) Committee on Education.

(ii) Committee on Standards. It was agreed that the committee should continue its work, as the need for standards for culture collections is still seen as important, but in a somewhat different direction from before, considering the guidelines being published. Some of the major target points are: (1) revision of the bylaws which give the criteria for affiliate membership (which is meant for culture collections), depending on the different kinds of collection, e.g., research collections, smaller collections, or developed service collections; (2) upgrading the checklist; and (3) preparation of a paper (questionnaire and checklist) for distribution to new affiliated collections, as well as annually to all collections to help keep up quality of performance.

(iii) Committee on Patents. It was noted that the task of this committee is now more a watching activity. The chair should be taken in turns by the different representatives of the International Depository Authority (IDA).

(iv) Committee on Endangered Culture Collections.

(v) Committee on Membership. This new committee had been set up to revise and tighten up the proceedings for membership: (1) how to get new members onto the system, (2) where membership applications should be sent to, (3) the dues structure. The proposals should be submitted to the EB for discussion.

(vi) Committee on World Data Center.

(vii) Committee on Postal, Quarantine, and Safety Regulations.

(viii) Committee on Biodiversity. This new committee was set up to distribute information, to liaise with other scientific organizations, and to write and publish scientific and popular articles to stress the importance of the topic.

(ix) Committee on Publications and Publicity.

Minute 6. Skerman Award. Unfortunately, the number of responses to the request for nominations for the Skerman Award was small. The only nominee was ineligible because he had passed the set age limit. Reasons for this could be that the request for nominations had not been made known widely enough and/or that it might be difficult to judge the scientific work of relatively young people as "outstanding." The situation was discussed, and it was agreed that the age limit should be retained because it should be a stimulating award and WFCC especially wants to encourage young people to enter taxonomy and systematics. The president will draw up statutes and forms to be used with a nomination to make judgement easier for those who are in a position to nominate. In addition to that, the next announcement for the Skerman Award will be made much more widely known.

Minute 7. ICCC-VII Proceedings. An Editorial Committee was set up to discuss the format and time table for the proceedings. The composition of the committee is Dr. L. Sly (Coordinator), Dr. V. Canhos, Dr. D. Fritze, and Dr. D.-K. Song. A formal invitation letter will be sent to all contributors and conveners to submit their written versions by March 1993. Provisionally, it was agreed that the symposium lectures should be 6 to 8 pages long and the round table lectures should be 3 to 4 pages long. For posters, the abstracts will be used which were originally submitted for the congress. A request will be sent to the United Nations Educational Programme (UNEP) to support printing of the manuscript.

Minute 8. Resolutions. The ICCC-VII resolutions were reconsidered. It was agreed that they will be published in the next WFCC newsletter and in a number of other publications.

Minute 9. Other business. The WFCC CODATA representative, Dr. M. Krichevsky, was approved. A proposal was made that in the future the WDC should be represented 
at the CODATA commission. It was agreed that from next term WDC director Dr. H. Sugawara should stand for WFCC in this commission.

An offer was made by WDC to house the central membership data base while working data bases are kept with the secretary and the treasurer. This offer was gratefully received to overcome the difficulties arising out of quadrennial change of officers. It was proposed that names and addresses of members be available on line but that all internal data be kept confidential.

Minute 10. ICCC-VIII (Venue, Theme, Organization). An application to host ICCC-VIII was made by Dr. D. van der Mei, Centralbureau voor Schimmelcultures, The Netherlands, which was accepted by the previous Board and announced to the assembly. Dr. van der Mei will be the
Chairman/Secretary of the Local Organizing Committee. This will be set up by him, and the composition will be reported to the $\mathrm{EB}$ in due course. The final theme and date will be discussed. Possible topics could include bioindustries, industrial involvement, medicine, sustainable developments, and the environment. In the meantime, important organizations will be alerted.

Minute 11. Date of next meeting. On the occasion of the IUMS Congress in Prague in 1994, WFCC will organize a satellite meeting. This occasion should also be used for the next EB meeting.

Minute 12. Adjournment. The meeting was adjourned at 6:00 p.m.

D. Fritze, Secretary 